\title{
EVALUATION OF NATURALLY DERIVED HYDROXYAPATITE TISSUE ENGINEERING SCAFFOLD COATED WITH CHITOSAN-CARBON NANOTUBES COMPOSITE
}

\author{
Salma M. Fathy *, Tarek A. Elkhooly ${ }^{* *}$, Ahmed A. Emam** and Fikry M. Reicha****
}

\begin{abstract}
Objective; This study aimed to valuate the effect of $f$-CNTs (functionalized carbon nanotubes) and chitosan (CS) composite on the mechanical properties and cell biocompatibility of carbonated HAp (hydroxyapatite) derived from cuttlefish bone.

Methods; The microstructure characterization of carbonated HAp after hydrothermal treatment showed complete transformation into highly crystalline structure. The prepared CS/fCNTs composite was introduced into HAp specimens under vacuum. A compressive load was applied till failure using a universal testing machine to evaluate compressive strength and elastic modulus of aragonite $\left(\mathrm{CaCO}_{3}\right)$ and treated HAp with $\mathrm{CS} / f$-CNTs composite. The proliferating number and percentage of MSCs (mesenchymal stem cells) in direct contact with tested materials were used as indication of cytotoxic effect after 24, 36 and 72 hours in addtion alkaline phosphatase activity (ALP) after 12 days was used as indication of osteogenic effect.
\end{abstract}

Results; The HAp group with deposition of CS/f-CNTs composite showed a statistically significant higher compressive strength $(0.82 \pm 0.17 \mathrm{MPa})$ and elastic modulus $(11.1 \pm 1.06 \mathrm{MPa})$ and a statistically significant lower value for cell viability percentage $(225,590 \pm 8030.503,32.95 \%)$ after 72 hours and ALP activity $(85.51 \pm 5.67 \mu \mathrm{U} / \mu \mathrm{g}$ protein) after 12 days of incubation.

Conclusions; Carbonated HAp scaffolds reinforced with CS/f-CNTs composite can be used in low stress bonny defects.

KEYWORDS: Cuttlefish, Bone scaffolds, Mechanical properties, Cytotoxicity.

\section{INTRODUCTION}

Various bonny defects like abnormal skeletal development or produced as a result of trauma or surgical excisions of tumors require to be restored with bone grafting materials. They should possess certain qualifications such as the high porosity with

\footnotetext{
* Dental Biomaterials Dept., Faculty of Oral and Dental Medicine, Zagazig University,

** Refractories, Ceramics and Building Materials Department, National Research Centre.

*** Medical Experimental Research Centre (MERC), Faculty of Medicine, Mansoura University,

**** Experimental Solid State Physics Dept., Faculty of Science, Mansoura University, Egypt
} 
substantial interconnectivity to allow for transport of oxygen, nutrients, attachment, proliferation and penetration of cells and exit of metabolic waste products. In addition, they should be biocompatible with appropriate biodegradable rate. Bone tissue scaffolds should also possess sufficient mechanical properties comparable to sites they are used for. ${ }^{1-3}$ Autogeneous bone grafts have been used successfully for long time but it is a kind of invasive procedure, as it needs a second operation in the harvesting site. Allograft is also an easy way to be used but it has a risk of infection or pathology transmission and immune system stimulation. These hazards may favor the usage of synthetic biomaterials, for example biodegradable polymers and bioactive ceramics, which needs more emphasis on their limited bone reparative ability together with the mechanical and other essential morphological scaffold properties. ${ }^{4,5}$ Several attempts were done to improve their osteogenic ability like the usage of osteogenic cells, growth or osteoinductive factors. ${ }^{1,6}$ However, previous reports claimed their ability to cause certain anomalies or elicit some tumor lesions..$^{7-9}$ The abnormal bone growth was also reported with three dimensional structures of hydroxyapatite (HAp) or tricalcium phosphate scaffolds. ${ }^{10}$ Although these materials were reported to be biocompatible, their in vivo usage may be questionable sometimes.

Despite of having minimal in vivo cytotoxicity, functionalized-carbon nanotube $(f$-CNT) were reported to improve the water miscibility, mechanical properties and biodegradability of HAp, chitosan and collagen biomaterials. So that, CNTs have gained the interest of researchers especially with their structure, which has high length, within microns, to diameter, within nanometers, ratio in addition to high strength and stiffness. Combination of CNTs, synthetic HA $\left\{\mathrm{Ca}_{10}\left(\mathrm{PO}_{4}\right)_{6}(\mathrm{OH})_{2}\right\}$ and chitosan was reported to produce a composite with improved properties. ${ }^{11-13}$ Despite of the bone repair ability of such synthetic HAp bioceramic as a result of its excellent biocompatibility and oesteoconductivity, ${ }^{14,15}$ carbonated HAp derived from natural sources like seashells, nacres and cuttlefish are gaining more interest. They have no stoichiometric structure and have multiple ion traces such as $\mathrm{CO}_{3}{ }^{2-}, \mathrm{Na}^{+}, \mathrm{Mg}^{2+}, \mathrm{Fe}^{2+}, \mathrm{F}^{-}$, and $\mathrm{Cl}^{-}$, which make them more closer to natural bone chemistry. ${ }^{16}$ Cuttlefish bone was reported to be a natural source for HAp with a low cost and extreme porosity $(\sim 90 \%)$, ideal pore size $(200-600 \mu \mathrm{m})$ and interconnectivity. ${ }^{17,18}$ However, as most HAp types it shows weak mechanical properties. Previous attempt depending on coating of the transferred aragonite of cuttlefish to HAp by biocompatible polymer like polycarbolactone (PCL) was reported..$^{19}$ Despite of improving the derived cuttlefish HAp mechanical properties, the former approach may result in coating of the bioactive and osteoconductive HAp surface and block the micro-irregularities that enhance cell attachment, proliferation and differentiation. So that the objective of this study was to study the effect of $f$-CNTs and chitosan composite on the mechanical properties of carbonated HAp source derived from cuttlefish bone and determine whether this would affect its cell biocompatibility.

\section{MATERIALS AND METHODS}

\section{Hydrothermal treatment of cuttlefish bone}

Cuttlefish bones (Sepia officinalis) from the Mediterranean Sea were harvested for this study. For compressive strength test, fish bone skeletons were carefully cut into sixty cubic-shaped specimens $(6 \times 6 \mathrm{~mm})$ and for cytocompatibility test thirty disc-shaped specimens $(6 \mathrm{~mm}$ in diameter X $3 \mathrm{~mm}$ thickness) were all carefully cut and placed within aqueous solution of sodium hypochlorite $(\mathrm{NaClO}, 5$ $\%$ active chlorine) for 2 days to remove the organic components. For their transformation into HAp, specimens were sealed with an aqueous solution of ammonium dihydrogen phosphate $\left(\mathrm{NH}_{4} \mathrm{H}_{2} \mathrm{PO}_{4}\right.$, anhydrous, 98-100.5\%, Sigma-Aldrich, Germany) with respecting the molar ratio of $\mathrm{Ca} / \mathrm{P}=1.67$. 
The hydrothermal treatment was done in a TEFLON lined stainless steel pressure vessel at $200{ }^{\circ} \mathrm{C}$ for 72 hours. After the treatment, bone specimens were washed three times with boiling distilled water and dried at $105^{\circ} \mathrm{C}$ in open air oven prior to use..$^{4,19}$

\section{Preparation of chitosan (CS)/CNTs composite}

A solution of medium molecular weight chitosan (CS) (deacetylated chitin, poly (D-glucoaseamine), Sigma-Aldrich) with concentration of $0.4 \%(\mathrm{~W} / \mathrm{V})$ was prepared in $0.2 \%(\mathrm{~V} / \mathrm{V})$ acetic acid under continuous stirring at ambient temperature until it became perfectly transparent. Simultaneously, multiwalled, carboxylic acid (-COOH) functionalized (> 8\% functionalization) carbon nanotubes ( $f$ ) $C N T s$ ) with average diameter $9.5 \mathrm{~nm} \&$ length 1.5 $\mu \mathrm{m}$ (Sigma-Aldrich, Germany) were dispersed in ethanol and sonicated for 15 minutes with 140-Watt ultrasonic power. Afterwards, the CS solution was added to the dispersed $f / C N T s$ with a weight ratio of 2.5:1 and stirred for 1.5 hours till homogeneous solution color was obtained.

\section{Preparation of $\mathrm{HAp}-\mathrm{CS}-\mathrm{f} / \mathrm{CNTS}$}

Twenty cubic-shaped and 10 disc shaped HAp scaffold specimens were immersed in $C S / f$ CNTs composite solution for ten minutes. Twenty milliliters of the former composite solution were used for every three specimens. Another $20 \mathrm{ml}$ of the solution were then allowed to pass through the porous specimens under vacuum for another ten minutes, both at room temperature. Specimens were finally washed with deionized water to remove excess unattached CS/f-CNTs composite. Another two groups of cubic and disc-shaped specimens were used, the first was as HAp control group and the second was as $\mathrm{CaCO}_{3}$ (raw cuttlefish bone) group before hydrothermal transformation into HAp.

\section{Characterization}

Phase microstructure of specimens was characterized at room temperature using X-ray diffractometer (X-Pert Pro, PANalytical B.V. company,
Caparica, Portugal) equipped with $\mathrm{CuK} \alpha$ radiation source generated at $40 \mathrm{kV}$ and $40 \mathrm{~mA}$ within the range of $2 \theta$ from $10^{\circ}$ to $70^{\circ}$ at a scan speed of $0.2^{\circ} \%$. Identification of the phases was performed by comparing the experimental XRD patterns to standards compiled by the Joint Committee on Powder Diffraction Standards (JCPDS). Other investigations were performed using Fourier Transformation Infrared (FTIR) Spectrophotometer (Thermo Fisher Scientific, Nicolet iS10, USA), 64 scans were collected for each measurement over the spectral range of $400-4000 \mathrm{~cm}^{-1}$ with a resolution of 4 $\mathrm{cm}^{-1}$, in addition to morphological assessments with field emission transmission electron microscope (2010FEF, JOEL, Japan).

\section{Compressive strength test}

A universal testing machine was used to apply maximum compressive load of $15 \mathrm{~N}$ at a crosshead speed of $0.2 \mathrm{~mm} / \mathrm{min}$ in ambient conditions on the cubic-shaped specimens. The load was applied perpendicular to lamellar structure of each specimen till failure. The elastic modulus and the compressive strength were calculated from the stress-strain curves. ${ }^{19}$

\section{Cytobiocompatibility}

The Mesenchymal stem cells (MSCs) were obtained from Medical Experimental Research Centre (MERC), Mansoura University, Egypt. They were isolated from 6-8 weeks old Sprague-Dawley female rat bones marrow after flushing the bone with low glucose (1000 mg/L)-Dulbecco's modified Eagle's medium (DMEM) containing 10\% fetal bovine serum (FBS), $1 \%$ penicillin, $1 \%$ streptomycin and $2 \mathrm{mM}$ glutamine, all were supplied from Lonza, Basel, Switzland. The cells were cultured in a controlled environment of $5 \% \mathrm{CO}_{2}$ at $37^{\circ} \mathrm{C}$. The cells were sub-cultured when they reached $70-80 \%$ confluence, and cells of passages 3-4 were used for the experiment. Cytobiocompitability was done through the following: 


\section{Cell proliferation assay}

The MSCs proliferation assay was used through cell counting using hemocytometer after trypsinization of the cells under phase contrast inverted microscope (Olympus America Inc., Pennsylvania USA) and Trypan Blue dye. The cell viability evaluation depends on the concept where viable cells do not take up impermeable dyes (Trypan Blue), but dead cells are permeable to the dye, so that only viable cell can be counted. After disinfection, six-well plates were used to incubate a number of 149,000 cells/well in direct contact with disc-shaped material specimens (10 specimens for each of the three groups) plus a control group (MSCs without any tested material). Material cell incubation was done in RPMI medium with $10 \%$ FBS (Invitrogen Cat. No. 12440046) in addition to $1 \%$ penicillin, $1 \%$ streptomycin and $2 \mathrm{mM}$ glutamine (Lonza, Basel, Switzland) under laminar air-flow, vertical class II biosafety cabinet, $37^{\circ} \mathrm{C}$ \& $\mathrm{CO}_{2}$ cell culture incubator for 24,48 and $72 \mathrm{~h}$. Cell proliferating number of viable cells by increase or decrease after the former periods was calculated.

\section{Osteogenic effect}

Before seeding the cells, the prepared disks of the tested materials were placed in six-well culture plate and treated for $2 \mathrm{~h}$ with $1 \%$ antibiotic/antimycotic solution. After disinfection, they were washed twice with phosphate buffered saline (PBS) and finally pre-wetted with culture media. Afterwards, specimens received a number of $3 \times 10^{4}$ MSCs in each $1 \mathrm{~mL}$ of osteogenic media with composition of DMEM, $10 \% \mathrm{FBS}, 1 \%$ penicillin, $1 \%$ streptomycin and $2 \mathrm{mM}$ glutamine (Lonza, Basel, Switzland), 50 $\mu \mathrm{g} / \mathrm{ml}$ ascorbic acid, $10 \mathrm{mM} \beta$-glycerophosphate, and $10 \mathrm{nM}$ dexamethasone (Sigma-Aldrich, Germany). The cells were allowed to be in direct contact with the material and incubated for $8 \mathrm{~h}$ prior to observation. A control group of the cells without the tested materials was used. The osteogenic supplements were refreshed every 2 days. After culturing for 12 days, osteogenesis was assessed by Alizarin Red staining and evaluation of ALP (alkaline phosphatase) enzyme activity.

\section{Alizarin red staining}

The cells were washed with PBS and fixed in $10 \%(\mathrm{v} / \mathrm{v})$ formaldehyde (Sigma, USA). After 15 min, 2\% Alizarin red solution at $p H 4.1$ was added to each flask. The cells were incubated at room temperature for $20 \mathrm{~min}$ and then they were washed four times with distilled water for $5 \mathrm{~min}$ each. Digital pictures of the proliferated cells after osteogenic differentiation at the surrounding area of the specimens were taken using inverted light microscope (Olympus America Inc., Pennsylvania USA). The pictures were taken with magnifications $4 \mathrm{x}$ and $10 \mathrm{x}$ of the lens.

\section{ALP activity}

The specimens were washed with PBS, and the cells were trypsinized and the cell pellets were resuspended in $100-200 \mu \mathrm{L}$ of the lysis buffer, and then centrifuged for $15 \mathrm{~min}$ at $2000 \mathrm{x}$ g. The ALP activity was assayed utilizing the conversion of a colorless p-nitrophenyl phosphate to a colored p-nitrophenol according to the manufacturer's protocol (Sigma, St. Louis, MO). The color change was measured spectrophotometrically at $405 \mathrm{~nm}$ (Spectra III, TECAN, Austria), and the alkaline phosphatase levels were normalized to the total protein content of cells measured by BCA assay Kit (Sigma, St. Louis, MO) according to the company's guidelines. The results were expressed in $\mu \mathrm{U}$ (micro unit) of yellow p-nitrophenol per micro- gram $(\mu \mathrm{g})$ of protein.

\section{Statistical analysis}

The results of the independent variables, mechanical properties (compressive strength and elastic modulus) and ALP activity, were analyzed using one-way analysis of variance (ANOVA). Factorial ANOVA analysis was done for analysis of cytotoxicity effect through proliferating MSCs 
number within the three intervals $(24,48$ and $72 \mathrm{~h}$ ). Prior to that, data were assessed to normality by means of Shapiro and Wilk test. Post hoc Tukey's test was used afterwards. All tests were accomplished using SPSS 16.0 (SPSS, Chicago, IL, USA) for Windows. Significance was predetermined at $\mathrm{P} \leq$ 0.05 . Results were expressed as mean \pm standard deviation (SD).

\section{RESULTS}

\section{Characterization properties}

The XRD pattern shows the raw cuttlefish bone with aragonite $\left(\mathrm{CaCO}_{3}\right)$ peak at $26.4^{\circ} 2 \theta$. After hydrothermal treatment (Fig. 1), the pattern shows well-resolved peaks of HAp at $2 \theta$ of $25.8^{\circ}$ and $31.8^{\circ}$, which indicates a high degree of crystallinity. There were no peaks corresponding to $\mathrm{CaCO}_{3}$ (aragonite) crystalline phase after hydrothermal treatment indicating its complete transformation into HAp. The SEM images of cuttlefish bone (Figure 2) show first the characteristic structure of fish bone as previously described. ${ }^{20}$ It is formed of cellular quasi-periodic microstructure consisting of lamellae separated by numerous pillars coated with organic material composed primarily of $\beta$-chitin. ${ }^{21}$ The interconnected structure of the cuttlefish bone was maintained after the hydrothermal conversion into HAp. Needle-shaped particles, at higher magnification $(\mathrm{x} 10,000)$, of HAp and its globular structure were recognized at lower magnification (x500). The Transmission Electron Microscope (TEM) (Fig. 3, a \& b) also shows the characteristic hexagonal shaped HAp crystals after hydrothermal transformation. The ordered periodic arrangement of atoms through the HAp crystal emphasizes on the high crystallinity of formed HAp.

The FTIR spectra (Fig. 1) show, first, bands assigned to carbonate group at 1,482, 1,452, 1,424 and $874 \mathrm{~cm}^{-1}$ were observed for the raw cuttlefish bone which are attributed to aragonite phase in consistent with XRD results. Second, after hydrothermal treatment, it shows the peaks of $\mathrm{PO}_{4}$ groups at bands of 1,092, 1,035, 961, 603 and 566 $\mathrm{cm}^{-1}$ correspondent to different vibration modes of phosphate group. On the other, the stretching and bending vibration band of hydroxyl group (OH) was observed at $3,570 \mathrm{~cm}^{-1}$. The functional

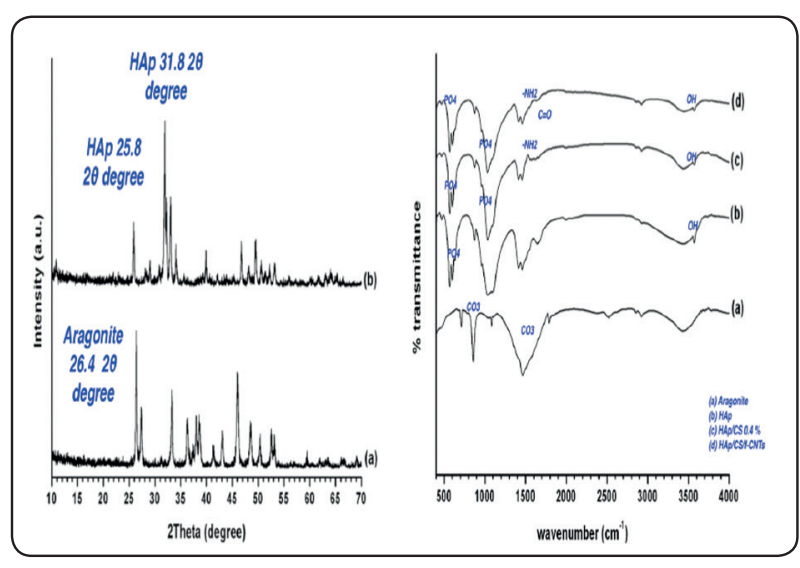

Fig. (1) XRD pattern (at left) of cuttlefish bone showing the prominent peaks for (a) aragonite phase before hydrothermal treatment and (b) HAp after hydrothermal treatment. Different FTIR patterns (at right), (a) raw cuttlefish bone, (b) phosphate groups and hydroxyl groups appearance after hydrothermal treatment, (c) CS functional groups are viewed, (d) HAp/CS/CNTs pattern.

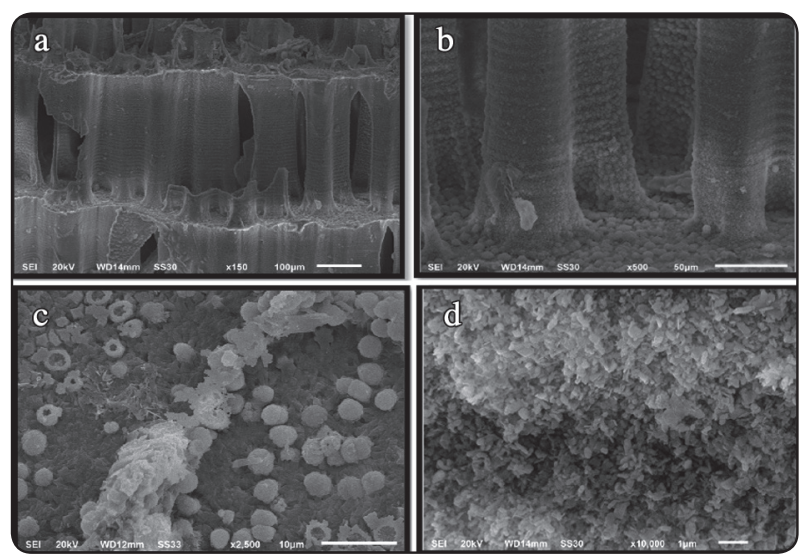

Fig. (2) SEM images (a) raw cuttlefish bone (x150), (b) transverse cross-section shows the interconnected channeled structure and globular structure of HAp after hydrothermal conversion (x500), (c) more mineralization over HAp surface $(x 2,500)$, (d) needlelike structure of formed HAp particles $(\mathrm{x} 10,000)$. 


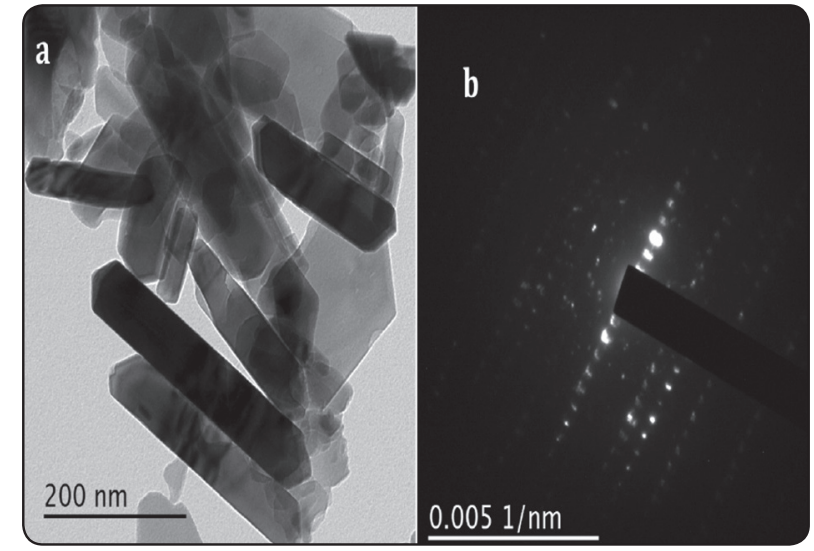

Fig. (3) TEM images showing (a) hexagonal shaped crystals of HAp, (b) organized atomic arrangement of formed HAp crystals.

groups of CS were assigned to bands of 1,638 and $1,566 \mathrm{~cm}^{-1}$ which are correspondent to amide I $(\mathrm{C}=\mathrm{O})$ and amino $\left(-\mathrm{NH}_{2}\right)$, respectively. The SEM images of cuttlefish after being coated with CS/f-CNTs composite (Fig. 4, top images) show the deposition of almost homogeneous distribution of $f$-CNTs on the HAp microspheres with keeping the roughness of the exposed areas of HAp and without coverage of whole bioactive and osteoconductive

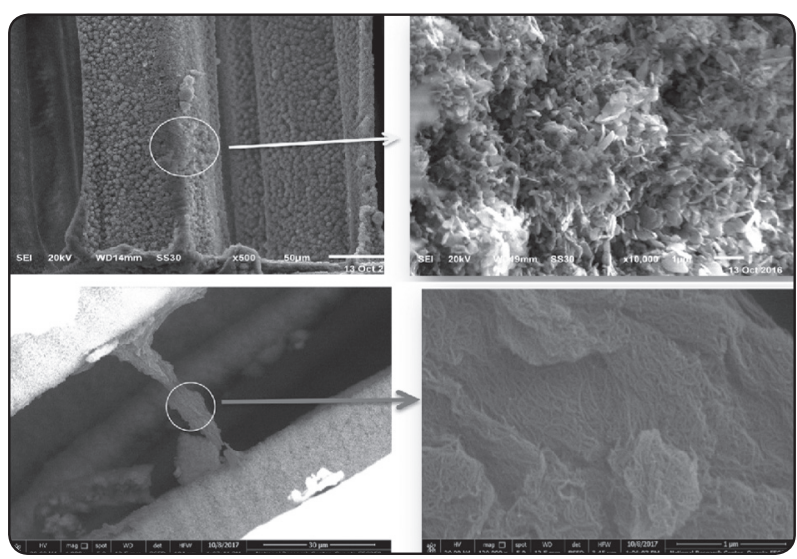

Fig. (4) Top images, SEM images of apparent HAp microspheres (x500) (on the left) and high magnification of f-CNTs deposited on HAp surface (x10,000) (on the right). Bottom images, SEM images of COOH-f-CNTs, low magnification $(x 4,000)$ extended across the cuttlefish bone pore (on the left) and high magnification (x120,000) showing the alignment of the nanotubes (on the right).
HAP surface. The agglomerated nanotubes (Fig. 4, bottom images) showed extension within the pore of cuttlefish that divide into two halves.

\section{Mechanical Properties}

There was a statistically significant increase $(\mathrm{p} \leq$ $0.05)$ within both compressive strength $(0.82 \pm 0.17$ $\mathrm{MPa})$ and young's modulus $(11.1 \pm 1.06 \mathrm{MPa})$ values of coated HAp group with $C S / f-C N T s$ composite than the other two groups. The stress-strain curve of both HAp and HAp/CS/f-CNTs specimens (Fig 5, a $\&$ b) show almost three different regions typical for porous structures. ${ }^{22}$ The initial increase in stress at low strain (linear-elastic region), which is followed by long fluctuating plateau region and final rapid decrease in stress due to brittle failure. The observed fluctuations in this region could be evidence for the layer-by-layer collapse of the microstructure under compression. The bar chart in Figure 5 shows mean values and standard deviations of tested mechanical properties with representative letters for post hoc Tukey's test.

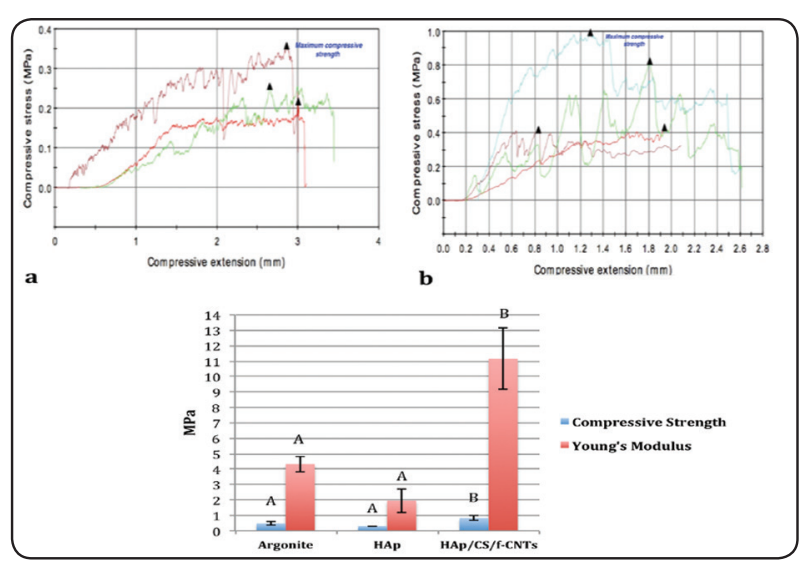

Fig. (5) Top images, stress-strain curves after compressive load application showing maximum compressive strength failure behavior of (a) HAp specimens, (b) HAp/CS/ CNTs coated specimens. Bottom image, Mechanical properties (compressive strength and elastic modulus) in MPa of all tested groups. Data are represented as mean \pm SD represented by error bars. P-value was $\leq$ 0.05 means there was significant difference and the letters are for Tukey's test. 


\section{Cytobiocompatibility}

\section{Cell proliferation assay}

The Two-way ANOVA showed a statistically significant difference $(P=0.00001)$ among all groups within three interval periods of incubation. HAp group showed the highest mean MSCs proliferating number $(246,667 \pm 8020.81)$ which was statistically insignificantly than that of HAp/ CS/f-CNTs group $(235,181 \pm 3241.81)$ and aragonite $(236,259 \pm 4183.003)$. Comparison among all groups regarding means and standard deviations of the number of proliferating MSCs after the three interval periods of incubation is shown in Figure 6 (a) with representative letters for Tukey's test.

\section{ALP activity (osteogenic ability)}

The ANOVA showed a statistically significant difference $(P=0.006)$ among all groups after 12 days of incubation. The HAp group showed the highest mean ALP activity $(112.4 \pm 8.61 \mu \mathrm{U} / \mu \mathrm{g}$ protein), which is statistically significant with the group coated with CS/f-CNTs $(90.85 \pm 8.18 \mu \mathrm{U} /$ $\mu \mathrm{g}$ protein) and control group $(85.51 \pm 5.68 \mu \mathrm{U} / \mu \mathrm{g}$ protein) after 12 days of incubation in direct contact with MSCs. Inverted light microscope images (Figure 10- A, B, C \& D) showed the MSCs with flatter or more irregular morphology. The bar chart in Figure 6 (b) shows means and standard deviations of ALP enzyme activity of all tested groups. Figure 7 shows irregular cell form of MSCs with calcified deposits formation.

TABLE (1) Means and standard deviations of compressive strength in addition to elastic moduli of all tested groups.

\begin{tabular}{|c|c|c|c|c|c|}
\hline \multicolumn{2}{|c|}{ Aragonite } & HAp & HAp/CS/f-CNTs & F-value & $P$-Value \\
\hline $\begin{array}{c}\text { Compressive Strength } \\
(\mathrm{MPa})\end{array}$ & $\mathbf{0 . 4 8} \pm 0.11^{\mathrm{A}}$ & $\mathbf{0 . 2 9} \pm 0.03^{\mathrm{A}}$ & $\mathbf{0 . 8 2} \pm 0.17^{\mathrm{B}}$ & $\mathbf{1 4 . 7}$ & \\
\cline { 1 - 4 } $\begin{array}{c}\text { Elastic Modulus } \\
(\mathrm{MPa})\end{array}$ & $\mathbf{4 . 3 3} \pm 0.5^{\mathrm{A}}$ & $\mathbf{1 . 9 5} \pm 0.7^{\mathrm{A}}$ & $\mathbf{1 1 . 1} \pm 1.06^{\mathrm{B}}$ & $\mathbf{2 1 . 1 7}$ & \\
\cline { 1 - 5 }
\end{tabular}

$P$-value $\leq 0.05$ means statistical significant difference and the letters are for Tukey's test.

TABLE (2) Means and standard deviations of Alkaline Phosphatase Activity (ALP) after 12 days of MSCs incubation with the tested groups.

\begin{tabular}{|c|c|c|c|}
\hline Material Group & APL $(\mu \mathrm{U} / \mu \mathrm{g}$ protein $)$ & F-value & P-value \\
\hline Aragonite & $\mathbf{1 0 0 . 7 8} \pm 4.06^{\mathrm{A}}$ & \multirow{2}{*}{13.321} & $\mathbf{0 . 0 5}$ \\
\hline HAp & $\mathbf{1 1 2 . 4} \pm \mathbf{8 . 6 1}^{\mathrm{AB}}$ & & \\
\hline HAp/CS/f-CNTs & $\mathbf{8 5 . 5 1} \pm \mathbf{5 . 6 7 ^ { \mathrm { AC } }}$ & & \\
\hline
\end{tabular}

$P$-value $\leq 0.05$ means statistical significant difference and the letters are for Tukey's test. 


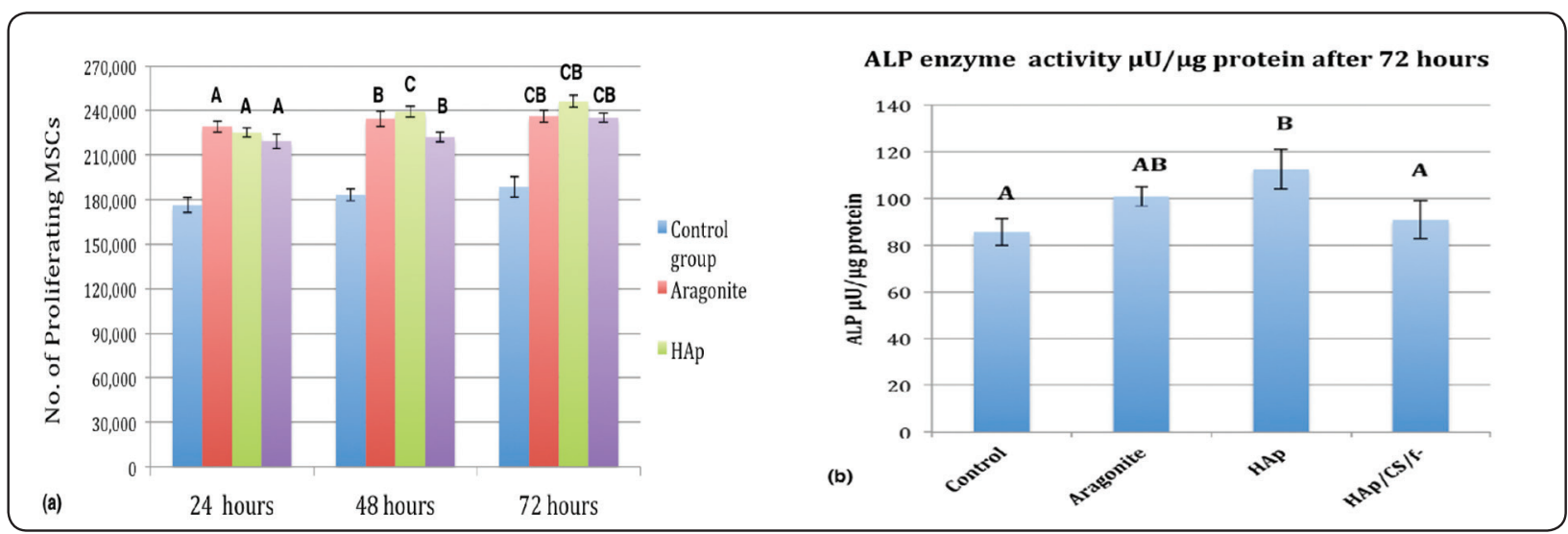

Fig. (6) The cell interaction with different groups (a) data of proliferating number of MSCs after 24, 48 and 72 hours intervals and (b) ALP activity ( $\mu \mathrm{U} / \mu \mathrm{g}$ protein) after 12 days of incubation with MSCs, all expressed as mean \pm SD represented by error bars. P-value was $\leq 0.05$ means there was significant difference and the letters are for Tukey's test.

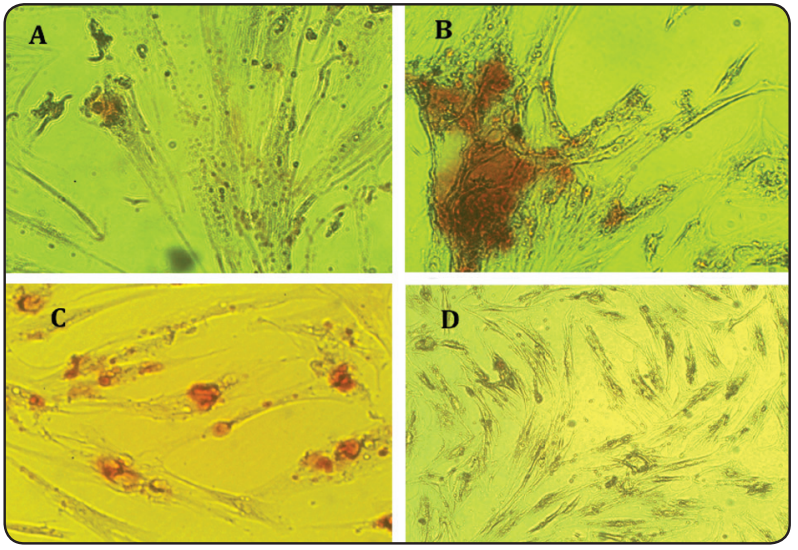

Fig. (7) Inverted light microscope images of (A) Control MSCs group, (B) Aragonite both with $\mathrm{x} 4$ lens, (C) HAp, (D) $\mathrm{HAp} / \mathrm{CS} / \mathrm{CNTs}$ with $\mathrm{x} 10$ lens, all in osteogenic media and after incubation for 12 days on direct contact with the tested material groups showing flatter or more irregular morphology of MSCs and stained calcium deposits.

\section{DISCUSSION}

This study focused on the deposition of $C S / f$-CNTS composite on the surface and within the architecture of cuttlefish bone, after its transformation from $\mathrm{CaCO}_{3}$ into HAp through hydrothermal treatment, under vacuum condition. ${ }^{19}$ This attempted to reinforce the cuttlefish bone and determine whether this would affect its cytobiocompatibility. The cuttlefish bone was reported to be a good source of carbonated HAp with a low cost, highly porous architecture $(\approx 90 \%)$ and interconnected porosity. It is considered as a biocompatible matrix for tissue engineering purpose except for poor mechanical properties especially after transformation into HAp through hydrothermal treatment.,17,19 The preparation of $H A p / C S / f-C N T S$ composite was previously done with various chemical methods 4,23-25 however, there was no previous attempt to apply $C S / f-C N T s$ to HAp within the architecture of cuttlefish bone. The use of multiwalled $f$-CNTs with carboxylic group for their potential to form strong non-covalent bonds to amine groups of chitosan, and bind electrostatically to calcium atoms on the interface of HAp crystals. ${ }^{26,27}$ Chitosan is a biocompatible natural polymer that was used in several researches on different tissue regeneration such as bone ${ }^{28,29}$ and drug carriers. ${ }^{30}$ It can degrade by human body enzymes into non-toxic products. ${ }^{31}$ It was classified as an antimicrobial agent against different organisms like bacteria, yeasts and fungi using different forms (solutions, films or composites) of chitosan. ${ }^{32}$ However, it does not have sufficient biocompatibility and needs combination with other bioactive materials such as HAp bioceramics as well as reinforcing phase like CNTs. ${ }^{33}$ 


\section{Mechanical properties}

Carbon nanotubes (CNTs) were previously used in tissue engineering field for reinforcement purpose, enhanced physical stability, bone regeneration, increase water miscibility (hydrophillicity) hence biocompatibility. ${ }^{13,34}$ The SEM images showed good dispersion of $f$-CNTs on the surface of formed HAp microspheres of cuttlefish bone in addition to IR results which revealed the appearance of vibration peaks of functional groups $\left(\mathrm{NH}_{2} \& \mathrm{C}=\mathrm{O}\right)$ in specimens contained $f$-CNTs. This indicates the possibility of their chemical interaction with this organic biocompatible polymer (chitosan) and also phosphate groups of HAp. The TEM images proved the formation of well-arranged atoms within HAp hexagonal crystals. The coated areas with surface dispersion of the organic-inorganic (CS/f-CNTs) complex may have acted as reinforcing phase for the brittle HAp structure which, in turn, reflected with a positive effect on compressive strength and elastic modulus values and significantly improved the mechanical behavior of the HAp coated group. The SEM images also showed $f$-CNT elongated alignment that extend and divide the bone pores into two parts. The tubes themselves were reported to have high strength and stiffness in addition to their small dimensions, high aspect ratio (length to diameter). ${ }^{26}$

The stress-strain curve of the coated cuttlefish specimens was typical to that previously discussed when the HAp globules within cuttlefish was coated using biocompatible polyesters like polycaprolactone (PCL) ${ }^{19}$ except for the last region. The material failed rapidly in the last region like most brittle materials although high stress levels it reached before failure. This may be explained by the fact of using a composite phase of stiff part $f$-CNT and tough part of chitosan polymer, that was chemically attracted and covered large areas of osteoconductive HAp without changing the micro-rough surface morphology, which favors the cell adhesion and proliferation unlike the case spreading a polymer phase all over the surface. ${ }^{19}$ The improved mechanical properties may also be correlated to possible filling of surface cracks by the reinforcing $C S / f$-CNT composite under the high vacuum force during its entrance. The compressive strength and elastic modulus of such prepared cuttlefish derived scaffolds are comparable to former reported literature and they are within lower border values reported for human bone. ${ }^{35,36}$ There is a great variation within the reported values for elastic modulus of trabecular human bone between 10 to $3000 \mathrm{MPa}$. This variation may be dependent on bone porosity, position and direction of load and the testing method used. This bone strength value is generally two orders of magnitude lower than the modulus value which is usually within the range of 0.1 to $30 \mathrm{MPa}{ }^{22}$ Therefore, this prepared scaffolds can be used for low stress bearing areas.

\section{Cytobiocompatibility}

Cytotoxicity of CNTs remained as a subject of contradiction for long time. Number of recent texts have reported their positive interaction and biocompatibility with the tissues in vivo, ${ }^{37,38}$ as new bone formation was detected after the implantation $\mathrm{CNT} / \mathrm{CS} / \mathrm{Si}$ (silica) membrane in vivo for 4 weeks without noticeable inflammatory response or foreign body reaction. ${ }^{39}$ This is, to great extent, in accordance with their performance in the recent study. Despite of having the lowest mean value among material groups for viable cell number after 72 hours of cytotoxicity assay, the HAP/CS/f-CNTs group showed significant increase in the viable cell number than the negative control group of MSCs alone denoting negligible cytotoxic effect. Relevant to cytotoxicity, the results of ALP activity where the HAP/CS/f-CNTs group showed the lowest values but still has the ability to cause MCSs differentiation into bone forming cells which has to be more verified in vivo in future studies. On the other hand, several previous studies have claimed a prominent cytotoxic effect of CNTs, especially 
the multi-walled (MWCNTs). ${ }^{40-42}$ They were reported to promote human epithelial cell death, ${ }^{43,44}$ human connective tissues, ${ }^{43}$ human cancer cell lines, which is regarded as a bright innovation for anti-cancer nanomedicines. ${ }^{45}$ Several factors were stated to control cell interaction with CNTs such as variability in length, diameter and functionalization, possible agglomeration and the concentration of the tubes as filler in addition to the type of cells used for in vitro assays..$^{39,46}$ The used amount of $f$-CNTs was relatively large, as chitosan to $f$-CNTs ratio was 2.5 , i.e. f-CNTs concentration was 0.16 $\%(\mathrm{~W} / \mathrm{V})$, which is higher than the reported level of non-toxic concentration of both $-\mathrm{OH}$ and $\mathrm{COOH}$ functionalized CNTs after 24 and 48 hours of cell proliferation assay. Despite of using this high concentration, the mechanism of depositing -COOH $f$-CNTs on cuttlefish external and internal surface had great effect on reducing this amount in each specimen which is completely different than the produced concentration after the chemical precipitation methods for preparing $H A p / C S / f-C N T s$. During vacuum impregnation, specimens were first dipped for 10 minutes (three specimens for each 20 $\mathrm{ml}$ of $C S / f-C N T s$ ) another $20 \mathrm{ml}$ of the $C S / f$-CNTS solution composite were allowed to be passing under vacuum through the porous specimens. Finally, specimens were washed with distilled water to remove any excess unattached $f$-CNTs. So that, minimal amount of $C S / f$-CNTs composite remained attached to cuttlefish surface as shown in the SEM images and the rest of solution was discarded. That was further justified by the neglected cytotoxic effect and the ability for cell differentiation ability for the group contained CS/f-CNTs composite. That is in addition to good dispersion on the surface and within pores of cuttlefish bone porosity that has good impact on interaction of the cells which is agreement with previous work of Li et al., 2013. ${ }^{47}$ It stated that aggregated nanotubes are more prone to come in contact with the cells in the well bottom causing their apoptosis which is in disagreement with the finding of Zhou L et al., 2017, where better dispersion of MWCNTs resulted in significantly greater interaction with cells causing low cell viability than groups of agglomerated nanotubes. This could be attributed to higher possibility of none aggregated MWCNTs to be free to reach cytoplasm and subsequently the nucleus causing apoptosis..$^{48,49}$ Future in vivo study on $\mathrm{HAP} / \mathrm{CS} / f$-CNTs tissue engineering scaffold should be considered for more evaluation of the former scaffold's cellular proliferation and differentiation effect.

\section{CONCLUSIONS}

Based on and within the limitations of the present study HAp scaffold derived from cuttlefish and reinforced with chitosan and $(-\mathrm{COOH})$ functionalized CNTs had compressive strength and elastic modulus values within reported levels of human trabecular bone. Though it gave the lowest values of cytotoxicity and proliferation ability on MSCs, it still has ability for cell differentiation with minimal cytotoxic effect. It can be considered as bone tissue engineering scaffold in low stress concentration areas within the jaw area.

\section{REFERENCES}

1. Chai YC, Carlier A, Bolander J, Roberts SJ, Geris L, Schrooten J, et al. Current views on calcium phosphate osteogenicity and the translation into effective bone regeneration strategies. Acta Biomater. 2012;8(11):3876-87.

2. Khan YM, Katti DS, Laurencin CT. Novel polymersynthesized ceramic composite-based system for bone repair: Anin vitro evaluation. J Biomed Mater Res [Internet]. 2004;69A(4):728-37. Available from: http:// doi.wiley.com/10.1002/jbm.a.30051

3. Navarro M, Ginebra MP, Planell JA,Zeppetelli S,Ambrosio L. Development and cell response of a new biodegradable composite scaffold for guided bone regeneration. J Mater Sci Mater Med. 2004;15(4):419-22.

4. Hongmin L, Wei Z, Xingrong Y, Jing W, Wenxin G, Jihong $\mathrm{C}$, et al. Osteoinductive nanohydroxyapatite bone substitute prepared via in situ hydrothermal transformation of cuttlefish bone. J Biomed Mater Res - Part B Appl Biomater. 2015;103(4):816-24. 
5. Salgado AJ, Coutinho OP, Reis RL. Bone tissue engineering: State of the art and future trends. Macromol Biosci. 2004;4(8):743-65.

6. Kawakatsu N, Oda S, Kinoshita A, Kikuchi S, Tsuchioka $\mathrm{H}$, Akizuki T, et al. Effect of rhBMP-2 with PLGA/gelatin sponge type (PGS) carrier on alveolar ridge augmentation in dogs. J Oral Rehabil. 2008;35(9):647-55.

7. Aguilar S, Nye E, Chan J, Loebinger M, Spencer-Dene B, Fisk N, et al. Murine but Not Human Mesenchymal Stem Cells Generate Osteosarcoma-Like Lesions in the Lung. Stem Cells. 2007;25(6):1586-94.

8. Tasso R, Augello A, Carida' M, Postiglione F, Tibiletti MG, Bernasconi B, et al. Development of sarcomas in mice implanted with mesenchymal stem cells seeded onto bioscaffolds. Carcinogenesis. 2009;30(1):150-7.

9. Wang RN, Green J, Wang Z, Deng Y, Qiao M, Peabody M, Zhang Q YJ, Yan Z, Denduluri S, Idowu O, Li M, Shen C, Hu A, Haydon RC, Kang R, Mok J, Lee MJ, Luu HL SL. Bone Morphogenetic Protein (BMP) Signaling in Development and Human Diseases. Genes Dis. 2014;1(1):87-105.

10. Habibovic P, Juhl M V., Clyens S, Martinetti R, Dolcini L, Theilgaard N, et al. Comparison of two carbonated apatite ceramics in vivo. Acta Biomater. 2010;6(6):2219-26.

11. Carson L, Kelly-brown C, Stewart M, Oki A, Regisford G, Luo Z, et al. Synthesis and characterization of chitosan - carbon nanotube composites. Mater Lett. 2009;63(67):617-20.

12. Facca S, Lahiri D, Fioretti F, Messadeq N, Mainard D, Benkirane-Jessel $\mathrm{N}$, et al. In vivo osseointegration of nano-designed composite coatings on titanium implants. ACS Nano. 2011;5(6):4790-9.

13. Tan W, Twomey J, Guo D, Madhavan K, Li M. Evaluation of nanostructural, mechanical, and biological properties of collagennanotube composites. IEEE Trans Nanobioscience. 2010;9(2):111-20.

14. Fathi MH, Hanifi A, Mortazavi V. Preparation and bioactivity evaluation of bone-like hydroxyapatite nanopowder. J Mater Process Technol. 2008;202(13):536-42.

15. Woodard JR, Hilldore AJ, Lan SK, Park CJ, Morgan AW, Eurell JAC, et al. The mechanical properties and osteoconductivity of hydroxyapatite bone scaffolds with multi-scale porosity. Biomaterials. 2007;28(1):45-54.
16. Peng H, Han Y, Liu T, Chauhari W, He C. Thermochimica Acta Morphology and thermal degradation behavior of highly exfoliated CoAl-layered double hydroxide / polycaprolactone nanocomposites prepared by simple solution intercalation. Thermochim Acta. 2010;502(12):1-7.

17. Rocha JHG, Lemos AF, Agathopoulos S, Kannan S, Valério P, Ferreira JMF. Hydrothermal growth of hydroxyapatite scaffolds from aragonitic cuttlefish bones. J Biomed Mater Res - Part A. 2006;77(1):160-8.

18. Rocha JHG, Lemos AF, Agathopoulos S, Valério P, Kannan S, Oktar FN, et al. Scaffolds for bone restoration from cuttlefish. Bone. 2005;37(6):850-7.

19. Milovac D, Gamboa-Martínez TC, Ivankovic M, Gallego Ferrer G, Ivankovic H. PCL-coated hydroxyapatite scaffold derived from cuttlefish bone: In vitro cell culture studies. Mater Sci Eng C. 2014;42:264-72.

20. Birchall JD \& Thomas NL. On the architecture and function of cuttlefish bone. J Mater Sci. 1983;18(7):2081-6.

21. Cadman J, Zhou S, Chen Y, Li Q. Cuttlebone: Characterisation, Application and Development of Biomimetic Materials. J Bionic Eng. 2012;9(3):367-76.

22. Goldstein SA. The mechanical dependence properties of trabecular bone: dependance on anatomic location and function. J Biomech. 1987;20(11):1055-61.

23. Chen L, Hu J, Shen X, Tong H. Synthesis and characterization of chitosan-multiwalled carbon nanotubes/hydroxyapatite nanocomposites for bone tissue engineering. J Mater Sci Mater Med. 2013;24(8):1843-51.

24. Li B, Huang L, Wang X, Ma J, Xie F, Xia L. Effect of micropores and citric acid on the bioactivity of phosphorylated chitosan/chitosan/hydroxyapatite composites. Ceram Int. 2013;39(3):3423-7.

25. Zhang X, Zhu L, Lv H, Cao Y, Liu Y, Xu Y, et al. Repair of rabbit femoral condyle bone defects with injectable nanohydroxyapatite/chitosan composites. J Mater Sci Mater Med. 2012;23(8):1941-9.

26. Venkatesan J, Qian Z-J, Ryu B, Kumar NA, Kim S-K. Preparation and characterization of carbon nanotube-grafted-chitosan - Natural hydroxyapatite composite for bone tissue engineering. Carbohydr Polym. 2011; 83(2):569-77.

27. Wang S-F, Shen L, Zhang W-D, Tong Y-J. Preparation and mechanical properties of chitosan/carbon nanotubes composites. Biomacromolecules. 2005;6(6):3067-72. 
28. Li Z, Yubao L, Aiping Y, Xuelin P, Xuejiang W, Xiang Z. Preparation and in vitro investigation of chitosan/ nano-hydroxyapatite composite used as bone substitute materials. J Mater Sci Mater Med. 2005;16(3):213-9.

29. Zhang Y, Ni M, Zhang M, Ratner B. Calcium PhosphateChitosan Composite Scaffolds for Bone Tissue Engineering. Tissue Eng. 2003;9(2):337-45.

30. Wang JJ, Zeng ZW, Xiao RZ, Xie T, Zhou GL, Zhan XR, et al. Recent advances of chitosan nanoparticles as drug carriers. Int J Nanomedicine. 2011;6(2):765-74.

31. Kumar MNVR, Muzzarelli RAA, Muzzarelli C, Sashiwa H, Domb AJ. Chitosan chemistry and pharmaceutical perspectives. Chem Rev. 2004;104(12):6017-84.

32. Goy RC, Britto D de, Assis OBG. A review of the antimicrobial activity of chitosan. Polímeros. 2009; 19(3):241-7.

33. White AA, Best SM, Kinloch IA. Hydroxyapatite-carbon nanotube composites for biomedical applications: A review. Int J Appl Ceram Technol. 2007;4(1):1-13.

34. Carson L, Kelly-Brown C, Stewart M, Oki A, Regisford G, Luo Z, et al. Synthesis and characterization of chitosan-carbon nanotube composites. Mater Lett. 2009; 63(6):617-20.

35. Kim H-W, Knowles JC, Kim H-E. Development of hydroxyapatite bone scaffold for controlled drug release via poly( $\varepsilon$-caprolactone) and hydroxyapatite hybrid coatings. J Biomed Mater Res. 2004;70B(2):240-9.

36. Zhao J, Duan K, Zhang JW, Lu X, Weng J. The influence of polymer concentrations on the structure and mechanical properties of porous polycaprolactonecoated hydroxyapatite scaffolds. Appl Surf Sci. 2010; 256(14):4586-90.

37. Firme CP \& Bandaru PR. Toxicity issues in the application of carbon nanotubes to biological systems. Nanomedicine Nanotechnology, Biol Med. 2010;6(2):245-56.

38. Terrones M, Souza Filho, A. G. \& Rao, A. M. Doped Carbon Nanotubes: Synthesis, Characterization and Applications. Appl Phys. 2008;111:531-66.

39. Seo SJ, Kim JJ, Kim JH, Lee JY, Shin US, Lee EJ, et al. Enhanced mechanical properties and bone bioactivity of chitosan/silica membrane by functionalized-carbon nanotube incorporation. Compos Sci Technol. 2014;96:31-7.
40. García-Hevia L, Fernández F, Grávalos C, García A, Villegas JC, Fanarraga ML. Nanotube interactions with microtubules: implications for cancer medicine. Nanomedicine. 2014;9(10):1581-8.

41. Villegas JC, Álvarez-Montes L, Rodríguez-Fernández L, González J, Valiente R, Fanarraga ML. Multiwalled Carbon Nanotubes Hinder Microglia Function Interfering with Cell Migration and Phagocytosis. Adv Healthc Mater. 2014;3(3):424-32.

42. Wang X, Guo J, Chen T, Nie H, Wang H, Zang J, et al. Multi-walled carbon nanotubes induce apoptosis via mitochondrial pathway and scavenger receptor. Toxicol Vitr. 2012;26(6):799-806.

43. Hamilton RF, Wu Z, Mitra S, Shaw PK, Holian A. Effect of MWCNT size, carboxylation, and purification on in vitro and in vivo toxicity, inflammation and lung pathology. Part Fibre Toxicol. 2013;10(1):57.

44. Muller J, Decordier I, Hoet PH, Lombaert N, Thomassen L, Huaux F, et al. Clastogenic and aneugenic effects of multiwall carbon nanotubes in epithelial cells. Carcinogenesis. 2008;29(2):427-33.

45. García-Hevia L, Valiente R, González J, Fernández-Luna JL, Villegas JC, Fanarraga ML. Anti-Cancer Cytotoxic Effects of Multiwalled Carbon Nanotubes. Curr Pharm Des. 2015;21(15):1920-9.

46. Wick P, Manser P, Limbach LK, Dettlaff-Weglikowska U, Krumeich F, Roth S, et al. The degree and kind of agglomeration affect carbon nanotube cytotoxicity. Toxicol Lett. 2007;168(2):121-31.

47. Li R, Wang X, Ji Z, Sun B, Zhang H, Chang CH, et al. Surface charge and cellular processing of covalently functionalized multiwall carbon nanotubes determine pulmonary toxicity. ACS Nano. 2013;7(3):2352-68.

48. Johnston HJ, Hutchison GR, Christensen FM, Peters S, Hankin S, Aschberger K, et al. A critical review of the biological mechanisms underlying the in vivo and in vitro toxicity of carbon nanotubes: The contribution of physico-chemical characteristics. Nanotoxicology. 2010;4(June):207-46.

49. Zhou L, Forman HJ, Ge Y, Lunec J. Multi-walled carbon nanotubes: A cytotoxicity study in relation to functionalization, dose and dispersion. Toxicol Vitr. 2017; 42(April):292-8. 